\title{
Antimicrobial activity of calcium hydroxide and chlorhexidine on intratubular Candida albicans
}

\author{
Ronan Jacques Rezende Delgado ${ }^{1}$, Thaís Helena Gasparoto ${ }^{1}$, Carla Renata Sipert ${ }^{1}$, Claudia Ramos Pinheiro ${ }^{1}$, \\ Ivaldo Gomes de Moraes ${ }^{2}$, Roberto Brandão Garcia ${ }^{2}$, Marco Antônio Hungaro Duarte ${ }^{2}$, Clóvis Monteiro \\ Bramante $^{2}$, Sérgio Aparecido Torres ${ }^{1}$, Gustavo Pompermaier Garlet ${ }^{1}$, Ana Paula Campanelli ${ }^{1}$ \\ and Norberti Bernardineli ${ }^{2}$
}

This study investigated the efficacy of calcium hydroxide and chlorhexidine gel for the elimination of intratubular Candida albicans (C. albicans). Human single-rooted teeth contaminated with $C$. albicans were treated with calcium hydroxide, $2 \%$ chlorhexidine gel, calcium hydroxide plus $2 \%$ chlorhexidine gel, or saline ( $0.9 \%$ sodium chloride) as a positive control. The samples obtained at depths of 0-100 and 100-200 $\mu \mathrm{m}$ from the root canal system were analyzed for $C$. albicans load by counting the number of colony forming units and for the percentage of viable $C$. albicans using fluorescence microscopy. First, the antimicrobial activity of calcium hydroxide and the $2 \%$ chlorhexidine gel was evaluated by counting the number of colony forming units. After 14 days of intracanal medication, there was a significant decrease in the number of $C$. albicans colony forming units at a depth of $0-100 \mu \mathrm{m}$ with chlorhexidine treatment either with or without calcium hydroxide compared with the calcium hydroxide only treatment. However, there were no differences in the number of colony forming units at the 100-200 $\mu \mathrm{m}$ depth for any of the medications investigated. $C$. albicans viability was also evaluated by vital staining techniques and fluorescence microscopy analysis. Antifungal activity against $C$. albicans significantly increased at both depths in the chlorhexidine groups with and without calcium hydroxide compared with the groups treated with calcium hydroxide only. Treatments with only chlorhexidine or chlorhexidine in combination with calcium hydroxide were effective for elimination of $C$. albicans.

International Journal of Oral Science (2013) 5, 32-36; doi:10.1038/ijos.2013.12; published online 29 March 2013

Keywords: calcium hydroxide; Candida albicans; chlorhexidine; endodontics

\section{INTRODUCTION}

The main objectives of endodontic treatment are elimination of microorganisms and prevention of reinfection within the root canal system. Resistant microorganisms can remain in the root canal system even after mechanical instrumentation and irrigation procedures because of its complex anatomy. ${ }^{1}$ Moreover, microbial persistence and growth in dentinal tubules, lateral canals and apical ramifications have also been shown. ${ }^{1-2}$ Many studies ${ }^{3-4}$ demonstrate the effectiveness of intracanal medications against antimicrobial resistant microorganisms. Additionally, these treatments control the persistent exudation and destructive action of osteoclasts during external root resorption. ${ }^{5-6}$ Polymicrobial endodontic infections are mainly composed of anaerobic species. ${ }^{7}$ Candida albicans (C. albicans) is the most commonly isolated yeast in root canal system infections, and the presence of $C$. albicans has been reported using culture, molecular and electron microscopy methods. ${ }^{8}$

Endodontic treatment may induce bacteria to enter a 'viable but non-culturable' (VBNC) state during which growth ceases, but the microorganisms remain viable. Yeasts are also capable to enter a VBNC state. ${ }^{9-10}$ When favorable conditions are reestablished, the microorganisms can return to a culturable state. ${ }^{11}$ The VBNC state could be evaluated by techniques that assess respiration, enzymatic activity and cellular activity by different methods. ${ }^{12-13}$ Among the various methods, fluorescence microscopy has been used to examine VBNC state. A fluorescence analysis is used commonly with vital staining techniques to determine the viability profile, architecture and spatial distribution in microbial biofilms. ${ }^{14}$

Due to the associated antimicrobial properties, calcium hydroxide $\left[\mathrm{Ca}(\mathrm{OH})_{2}\right]$ has been widely used as an intracanal medication, ${ }^{15}$ despite the limited action against Enterococcus faecalis (E. faecalis) ${ }^{1}$ and $C$. albicans. ${ }^{15}$ Comparatively, chlorhexidine emerged as an intracanal medication because of persistent antimicrobial action when adhered to anionic substrates. ${ }^{16}$ The combination of $\mathrm{Ca}(\mathrm{OH})_{2}$ and chlorhexidine resulted in antimicrobial properties that were more effective than treatment with $\mathrm{Ca}(\mathrm{OH})_{2}$ only and did not affect the sealing ability of root canal obturation. ${ }^{17}$ However, a recently study shows

\footnotetext{
${ }^{1}$ Department of Biological Sciences, Bauru School of Dentistry, University of São Paulo, Bauru, Brazil and ${ }^{2}$ Department of Operative Dentistry, Endodontics and Dental Materials, Bauru School of Dentistry, University of São Paulo, Bauru, Brazil

Correspondence: Dr RJR Delgado, Department of Biological Sciences, Bauru School of Dentistry, University of São Paulo, 9-75 Alameda Dr. Octávio Pinheiro Brisolla, Bauru 17012-901, Brazil 
that chorhexidine reduced the success of root canal treatment. ${ }^{18}$ Understanding the antimicrobial chlorhexidine efficacy toward endodontic infections should enhance interpretation of clinical results. Although some clinical studies have supported the efficacy of calcium hydroxide as an intracanal medicament, other studies have questioned its efficacy and indicated chlorhexidine instead of calcium hydroxide. ${ }^{19}$ Therefore, this study used both culture and fluorescence microscopy methods to investigate whether treatment with chlorhexidine only or in combination with $\mathrm{Ca}(\mathrm{OH})_{2}$ could eliminate C. albicans.

\section{MATERIALS AND METHODS}

\section{Teeth preparation}

The experimental protocol was approved by the local Institutional Ethical Committee (28/2006). Sixty-four extracted single-rooted teeth were cleaned with periodontal curettes to remove periodontal tissue and stored in $10 \%$ formaldehyde for 2 weeks, then they were washed under running water for $48 \mathrm{~h}$, blot dried and stored in $0.9 \%$ sterile saline at $4{ }^{\circ} \mathrm{C}$ for no longer than 7 days: ${ }^{20-21}$ Fifteen teeth served as the positive control, fifteen teeth were in each of the three experimental groups, two teeth were prepared to analyze the effectiveness of smear layer removal and two teeth were used to confirm C. albicans contamination by scanning electron microscopy. Specimens were prepared as previously described. ${ }^{2-23}$ Briefly, the crowns $(2-3 \mathrm{~mm}$ from the cement-enamel junction) and apical portion of the roots $(3-5 \mathrm{~mm})$ were removed. Biomechanical preparations were performed using \#15-\#40 K-files (Dentsply Maillefer, Ballaigues, Switzerland). All teeth were submitted to an ultrasonic bath for $10 \mathrm{~min}$ in $17 \%$ ethylene diaminetetraacetic acid (EDTA) (Farmácia Flor \& Ser Manipulação, São Paulo, Brazil) followed by $10 \mathrm{~min}$ in $5.25 \% \mathrm{NaClO}$ (Farmácia Flor \& Ser Manipulação, São Paulo, Brazil) to eliminate the smear layer. ${ }^{24}$ Then, the specimens were stored in $0.9 \%$ sterile saline until the experimental procedures were performed.

\section{C. albicans growth}

C. albicans (ATCC 10231) was cultured in Sabouraud broth. Yeast cell morphology was confirmed using the Gram method and a stereomicroscope (MS 23358; Wild Heerbrugg, Romanshorn, Switzerland). Cell counts and concentrations were determined using a Neubauer chamber (Propper Manufacturing, Long Island City, NY, USA).

\section{Experimental root canal infection}

The roots were placed in test tubes containing $5 \mathrm{~mL}$ of Sabouraud broth, and $1.5 \times 10^{8}$ C. albicans cells were diluted in $5 \mathrm{~mL}$ of medium, which maintained contact between the yeast suspension and root canal walls. ${ }^{22-23}$ Fresh Sabouraud broth was supplemented weekly to ensure C. albicans viability. All specimens were incubated aerobically at $37{ }^{\circ} \mathrm{C}$ for 21 days. These incubations were examined daily, and the turbidity for each sample was recorded. C. albicans contamination of dentinal tubules was confirmed using scanning electron microscopy. After this period, each root canal was irrigated with $5 \mathrm{~mL}$ of $0.9 \%$ sterile saline, dried with sterile paper points, and divided into four groups $(n=15)$.

\section{Intracanal dressings}

Teeth samples were submitted to the following intracanal dressings:

Group I (15 samples): $\mathrm{Ca}(\mathrm{OH})_{2}$ paste (Calen; S.S.WHITE Artigos dentários Ltd, Rio de Janeiro, RJ, Brazil).

Group II (15 samples): 2\% chlorhexidine gel (chlorhexidine gluconate plus 1\% natrosol gel) (Flor \& Ser- Farmácia de ManipulaçãoBauru, São Paulo, Brazil).
Group III (15 samples): $\mathrm{Ca}(\mathrm{OH})_{2}$ paste combined with $2 \%$ chlorhexidine gel $(1: 1)$.

Group IV (15 samples): 0.9\% sterile saline $(\mathrm{NaCl})$ (positive control).

Each dressing was applied under sterile conditions using a syringe and needle to completely fill each root canal. After the excess dressing was removed, coronal and apical orifices were sealed with temporary restorative cement (Saint Maur des Fosses, Paris, France). The specimens were then placed into Petri dishes, covered with damp sterile gauze and incubated at $37{ }^{\circ} \mathrm{C}$ for 14 days.

\section{Dentinal fragment samples}

After the incubation period, the restorative cement was removed, and the experimental samples were irrigated with $5 \mathrm{~mL}$ of sterile saline. Subsequently, root canals were irrigated with $1 \mathrm{~mL}$ of neutralizing solution for each antimicrobial agent: $0.5 \%$ citric acid for $\mathrm{Ca}(\mathrm{OH})_{2}$ and $0.5 \%$ Tween 80 in $0.07 \%$ soy lecithin for $2 \%$ chlorhexidine gel and for $2 \%$ chlorhexidine gel combined with $\mathrm{Ca}(\mathrm{OH})_{2}$. A final irrigation with $1 \mathrm{~mL}$ of sterile saline was then performed, and all root canals were dried with sterile paper points.

The amount of dentin scrapings was weighed, and the concentration was adjusted per mg of scrapings. Dentinal fragment samples were collected using Gates Glidden Drills: \#5 for a depth of 0-100 $\mu \mathrm{m}$ and \#6 for a depth of 100-200 $\mu \mathrm{m}\left(500 \mathrm{r} \cdot \mathrm{min}^{-1}, 1 \mathrm{~N}\right.$, electric motor K Driller Endo Plus). The roots were positioned in microcentrifuge tubes containing $1 \mathrm{~mL}$ of BHI (brain heart infusion) broth to collect scrapings at a depth of $0-100 \mu \mathrm{m}$ or at a depth of $100-200 \mu \mathrm{m}$. For all of the samples, bur \#5 and also \#6 were used each one for three times for the entire length of the root canal. After use, the burs were discarded, and new sterilized burs were used for another tooth. To prevent contamination between 0-100 $\mu \mathrm{m}$ and 100-200 $\mu \mathrm{m}$ samples, the burs were rotated in seventy alcohol solution, followed by distilled water and finally rotated in phosphate-buffered solution (PBS).

\section{Scanning electron microscopy}

Four similarly prepared tooth samples were used for scanning electron microscopy evaluation. Two teeth were prepared to analyze the effectiveness of smear layer removal, and two teeth were used to confirm C. albicans contamination. The teeth were bisected longitudinally, irrigated with EDTA $+\mathrm{NaClO}$ or PBS as control, and incubated as described above. After fixation, dehydration and gold coating, the samples were examined under scanning electron microscopy (Phillips XL30 FEG; Philips, Eindhoven, The Netherlands). ${ }^{21}$

\section{Assessment of antimicrobial activity}

Immediately after collection, dentine samples were mixed for $1 \mathrm{~min}$. Aliquots of $25 \mu \mathrm{L}$ were seeded on Sabouraud agar and incubated at $37{ }^{\circ} \mathrm{C}$ for $48 \mathrm{~h}$. After incubation, colony forming units (CFUs) were counted using a CP600 colony counter (Quimis Aparelhos Científicos, Diadema, SP, Brazil). To determine the CFU $\cdot \mathrm{mL}^{-1}$, the number of microorganisms growing in the plate was multiplied by the dilution factor and by the volume used to seed the plate. ${ }^{25}$ The procedure was performed in triplicate. C. albicans purity was confirmed by colony morphology and Gram staining.

For fluorescence microscopy analysis, the dentin suspensions were mixed for $30 \mathrm{~s}$, centrifuged at $600 \mathrm{~g}$ for $5 \mathrm{~min}$ and washed with PBS. Each pellet was suspended in $25 \mu \mathrm{L}$ of PBS by vigorous agitation. The samples were stained with $25 \mu \mathrm{L}$ of fluorescein diacetate (viable yeast cells were stained green) and $25 \mu \mathrm{L}$ of ethidium bromide (nonviable yeast cells were stained red) at $37^{\circ} \mathrm{C}$ for $15 \mathrm{~min}$ and then analyzed using 
confocal microscopy (TCS model, SPE; Leica, Mannheim, Germany). Yeast viability was expressed as the mean percentage of viable C. albicans over the total number of microorganisms by randomly counting three fields in three different microscope slides $(\times 40$ $\times 100$ magnification). ${ }^{26}$ The wavelength used to visualize fluorescein diacetate was 488 and $568 \mathrm{~nm}$ was used for ethidium bromide.

\section{Statistical analysis}

The results are expressed as the means \pm s.d. Two-way analysis of variance followed by Bonferroni's test was employed, and significant differences were considered as $P<0.05$. GraphPad PRISM (version 5) was used for graphic representations.

\section{RESULTS}

\section{Antimicrobial activity of chlorhexidine and $\mathrm{Ca}(\mathrm{OH})_{2}$ against} C. albicans

The effectiveness of smear layer removal was analyzed (Figure 1a). After a twenty-one-day period, C. albicans contamination of dentinal tubules was confirmed by scanning electron microscopy (Figure 1b).

The antimicrobial activity of $\mathrm{Ca}(\mathrm{OH})_{2}$ and $2 \%$ chlorhexidine gel was evaluated by counting the number of CFUs. The use of $\mathrm{Ca}(\mathrm{OH})_{2}$ and $2 \%$ chlorhexidine in combination and separately significantly reduced the number of $C$. albicans $\mathrm{CFUs}$ recovered at depths of 0 100 and $100-200 \mu \mathrm{m}$ compared with the control (Figure 2). A significant decrease was observed in C. albicans CFUs from a $0-100 \mu \mathrm{m}$
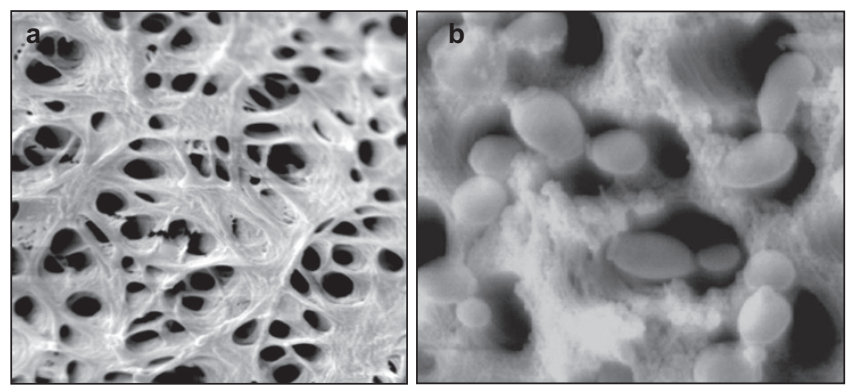

Figure 1 Scanning electron microscopy image. (a) Showing smear layer removal. (b) Showing C. albicans in human dentinal tubules 21 days after infection.

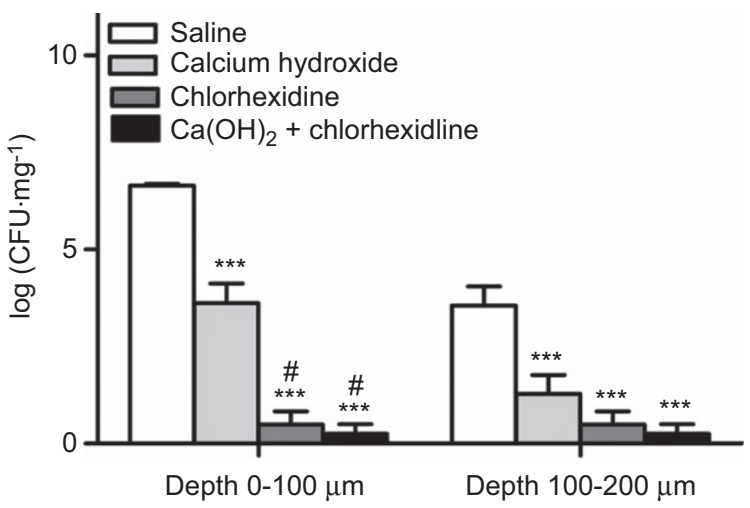

Figure 2 Antimicrobial activity of intracanal dressings against intratubular C. albicans. The bars show the number of CFUs of $C$. albicans recovered after $\mathrm{Ca}(\mathrm{OH})_{2}$ and chlorhexidine treatment. The results are represented as the mean \pm s.d. The data were analyzed by two-way ANOVA followed by Bonferroni's test. $* * * P<0.01$ compared with the control; ${ }^{\#} P<0.01$ compared with $\mathrm{Ca}(\mathrm{OH})_{2}$. ANOVA, analysis of variance; CFU, colony forming unit.

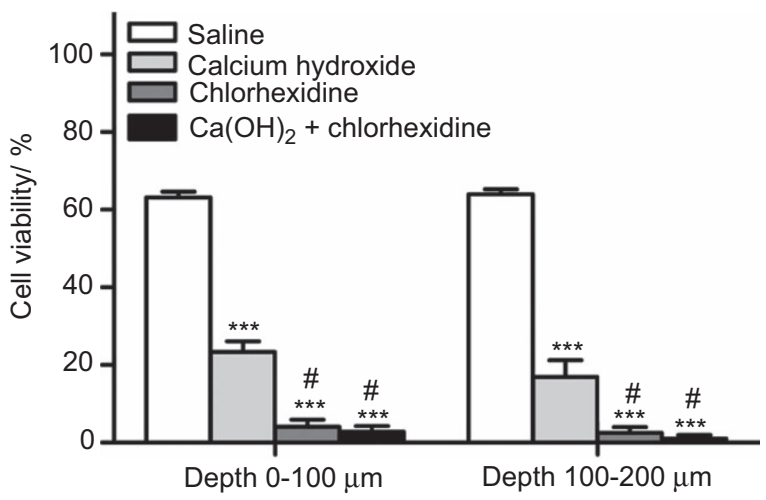

Figure 3 Viability of $\boldsymbol{C}$. albicans. The antimicrobial activity of $\mathrm{Ca}(\mathrm{OH})_{2}$ and the $2 \%$ chlorhexidine gel was analyzed by fluorescence microscopy. The results are represented as the mean \pm s.d. The data were analyzed by two-way ANOVA followed by Bonferroni's test. *** $P<0.01$ compared with the control; ${ }^{\#} P<0.01$ compared with $\mathrm{Ca}(\mathrm{OH})_{2}$. ANOVA, analysis of variance.
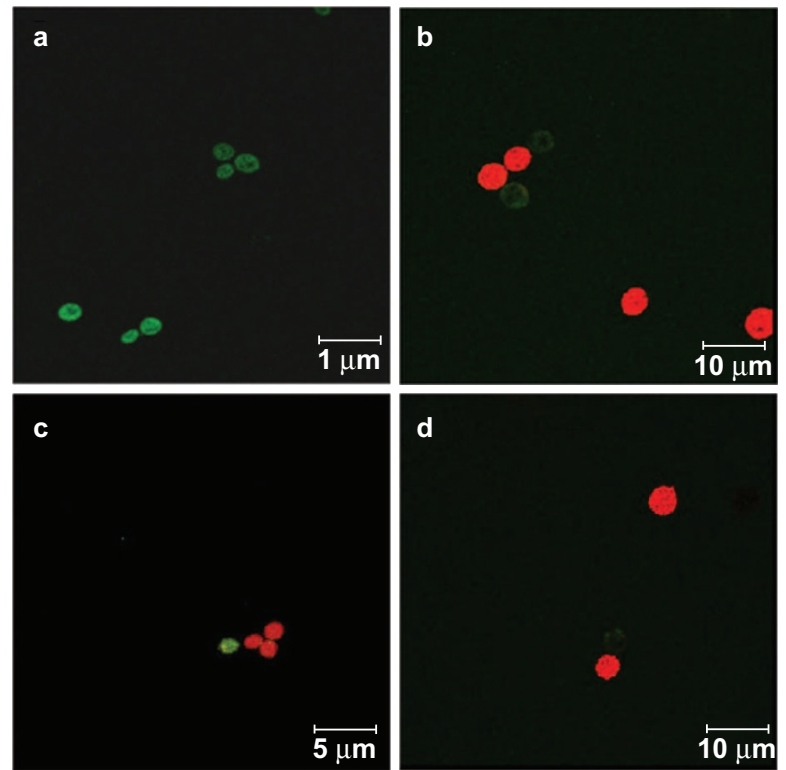

Figure 4 C. albicans viability after treatment. (a) With saline solution. (b) With calcium hydroxide. (c) With $2 \%$ chlorhexidine gel. (d) With $\mathrm{Ca}(\mathrm{OH})_{2}$ combined with $2 \%$ chlorhexidine gel. Images were obtained at $\times 40$ magnification (a and $\mathbf{c}$ ) and $\times 100$ magnification ( $b$ and $\mathbf{d}$ ).

depth after treatment with chlorhexidine with or without $\mathrm{Ca}(\mathrm{OH})_{2}$ compared with treatment with $\mathrm{Ca}(\mathrm{OH})_{2}$ only (Figure 2 ). However, no differences were observed at a depth of 100-200 $\mu \mathrm{m}$ for any of the antimicrobial medications (Figure 2).

C. albicans viability was also evaluated by vital staining technique and fluorescence microscopy analysis (Figure 3). The intracanal dressings significantly reduced the percentage of viable yeast compared with the control $(P<0.001)$ (Figures 3 and $4 a$ ). Antifungal activity against $C$. albicans significantly increased at both depths in the chlorhexidine groups with or without $\mathrm{Ca}(\mathrm{OH})_{2}(P<0.001)$ compared with the groups treated with $\mathrm{Ca}(\mathrm{OH})_{2}$ only (Figures 3 and 4 ).

\section{DISCUSSION}

Considered as one of the most resistant species in the oral cavity, C. albicans is a possible cause of root canal system treatment failure. ${ }^{3,27}$ Biofilms 
containing C. albicans have important clinical relevance and exhibit increased resistance to antifungal therapy and host immune defenses. ${ }^{8,28}$

In the present work, the impact of chlorhexidine and $\mathrm{Ca}(\mathrm{OH})_{2}$ on the survival of intratubular C. albicans was evaluated by counting the number of CFUs and yeast viability using fluorescence microscopy. Different techniques are often used to determine the antibacterial activity of dental materials and for clinical research. CFU is a measure of viable bacterial or fungal cells. However, this method does not provide clear information about the spatial distribution of bacteria inside the dentin and the density of VBNC microbial population cannot be estimated. In contrast, a fluorescence analysis provides information regarding the proportion of responsive cells to a substrate within a population, showing a direct and precise estimation of live/ dead cells. Fluorescent staining with ethidium bromide is a specific method to identify viable and nonviable cells because ethidium bromide only penetrates cells with damaged plasmalemmas. ${ }^{29-30}$ The results obtained in this study confirm the ability of these two techniques to determine the viability of $C$. albicans in the samples and allow for the recovery of microorganisms within dentinal tubules rather than planktonic yeast suspended in the lumen of root canal system. ${ }^{31-32}$

Intracanal medication significantly reduced C. albicans CFUs at both depths investigated. Additionally, there was a significant difference at the $0-100 \mu \mathrm{m}$ depth between $\mathrm{Ca}(\mathrm{OH})_{2}$ treatment with or without chlorhexidine, but not at the 100-200 $\mu \mathrm{m}$ depth for these respective treatments. Even when using the same methodology, these results do not corroborate those observed with E. faecalis, ${ }^{33}$ which may be due to the different abilities of $C$. albicans and $E$. faecalis to penetrate dentinal tubules. ${ }^{34-35}$ However, chlorhexidine with and without $\mathrm{Ca}(\mathrm{OH})_{2}$ significantly increased antifungal activity against $C$. albicans compared with the groups treated with $\mathrm{Ca}(\mathrm{OH})_{2}$ only. The effectiveness of chlorhexidine against C. albicans and E. faecalis has been shown previously. ${ }^{7,15}$ Chlorhexidine is a broad-spectrum bactericidal and fungicidal agent that prevents microbial colonization on the dentine surface for a prolonged period of time..$^{7,9,16,36}$ It is important to note that there are several factors that could be influenced the results of an in vitro study, such as smear layer removal, the type of intracanal medication tested and the evaluation method, among others. ${ }^{37}$

Studies have reported that the antimicrobial activity of chlorhexidine is reduced when used in combination with $\mathrm{Ca}(\mathrm{OH})_{2}{ }^{38}$ however, the present study show similar antimicrobial activity for chlorhexidine combined with $\mathrm{Ca}(\mathrm{OH})_{2}$ and chlorhexidine alone against $C$. albicans. These data are corroborated by a previous study by Zerella et al. ${ }^{17}$ who compared the effect of $\mathrm{Ca}(\mathrm{OH})_{2}$, chlorhexidine and their combination on the disinfection of the pulp space of failed root-filled teeth during endodontic retreatment. The combination of chlorhexidine with $\mathrm{Ca}(\mathrm{OH})_{2}$ paste could remain in the root canal system as a barrier for longer periods, which may eliminate a significant proportion of persistent microorganisms. ${ }^{39}$

$\mathrm{Ca}(\mathrm{OH})_{2}$ is an intracanal medication typically used in endodontics and has an antimicrobial property related to the release of hydroxyl ions. ${ }^{15}$ Although $\mathrm{Ca}(\mathrm{OH})_{2}$ effectively eliminates most endodontic pathogens, studies have demonstrated that E. faecalis and C. albicans are resistant to $\mathrm{Ca}(\mathrm{OH})_{2}{ }^{1,15,36}$ In this work, the results corroborated previous study and indicate that treatment with $\mathrm{Ca}(\mathrm{OH})_{2}$ alone killed $C$. albicans, however, with minor effectiveness than treatment with chlorhexidine alone.

\section{CONCLUSION}

Treatment with chlorhexidine or chlorhexidine in combination with $\mathrm{Ca}(\mathrm{OH})_{2}$ was effective antimicrobial against $C$. albicans when used as an intracanal medicament being more effective than treatment with $\mathrm{Ca}(\mathrm{OH})_{2}$ alone.

\section{ACKNOWLEDGEMENTS}

This work was supported by Fundação de Amparo à Pesquisa do Estado de São Paulo (scholarship to CRS (2007/00306-1) and THG (2009/14127-7)), Coordenação de Aperfeiçoamento de Pessoal de Nível Superior (scholarship to CRP) and Conselho Nacional de Desenvolvimento Científico e Tecnológico (scholarship to MAHD, GPG and APC). Publication of this manuscript is supported by Open Fund of State Key Laboratory of Oral Diseases, Sichuan University.

1 Turk BT, Sen BH, Ozturk T. In vitro antimicrobial activity of calcium hydroxide mixed with different vehicles against Enterococcus faecalis and Candida albicans. Oral Surg Oral Med Oral Pathol Oral Radiol Endod 2009; 108(2): 297-301.

2 Vianna ME, Gomes BP. Efficacy of sodium hypochlorite combined with chlorhexidine against Enterococcus faecalis in vitro. Oral Surg Oral Med Oral Pathol Oral Radiol Endod 2009; 107(4): 585-589.

3 Valera MC, Silva KC, Maekawa LE et al. Antimicrobial activity of sodium hypochlorite associated with intracanal medication for Candida albicans and Enterococcus faecalis inoculated in root canals. J App/ Oral Sci 2009; 17(6): 555-559.

4 Valera MC, da Rosa JA, Maekawa LE et al. Action of propolis and medications against Escherichia coli and endotoxin in root canals. Oral Surg Oral Med Oral Pathol Oral Radiol Endod 2010; 110(4): 70-74

5 Matsuo T, Shirakami T, Osaki K et al. An immunohistochemical study of the localization of bacterial invading root pulpal walls of teeth with periapical lesions. J Endod 2003; 29(3): 194-200.

6 Möller AJ, Fabricius L, Dahlén G et al. Apical periodontitis development and bacterial response in endodontic treatment. Experimental root canal infections in monkeys with selected bacterial strains. Eur J Oral Sci 2004; 112(3): 207-215.

7 Chandra SS, Miglani R, Srinivasan MR et al. Antifungal efficacy of $5.25 \%$ sodium hypochlorite, $2 \%$ chlorhexidine gluconate, and 17\% EDTA with or without an antifungal agent. J Endod 2010; 36(4): 675-678.

8 Baumgartner JC, Watts CM, Xia T. Occurrence of Candida albicans in infection of endodontic origin. J Endod 2000; 26(12): 695-698.

9 Agnolucci M, Rea F, Sbrana $\mathrm{C}$ et al. Sulphur dioxide affects culturability and volatile phenol production by Brettanomyces/Dekkera bruxellensis. Int J Food Microbiol 2010; 143(1/2): 76-80.

10 Liao $\mathrm{H}$, Zhang $\mathrm{L}$, $\mathrm{HuX}$ et al. Effect of high pressure $\mathrm{CO}_{2}$ and mild heat processing on natural microorganisms in apple juice. Int J Food Microbiol 2010; 137(1): 81-87.

11 Oliver JD. The viable but nonculturable state in bacteria. J Microbiol 2005; 43(Spec No): 93-100.

12 Roszak DB, Colwell RR. Metabolic activity of bacterial cells enumerated by direct viable count. Appl Environ Microbiol 1987; 53(12): 2889-2893.

13 Barcina I. Survival strategies of enteric bacteria in aquatic systems. Microbiologia 1995; 11(3): 389-392.

14 Zaura-Arite E, van Marle J, Ten Cate JM. Conofocal microscopy study of undisturbed and chlorhexidine-treated dental biofilm. J Dent Res 2001; 80(5): 1436-1440.

15 Ballal V, Kundabala M, Acharya S et al. Antimicrobial action of calcium hydroxide, chlorhexidine and their combination on endodontic pathogens. Aust Dent J 2007; 52(2): 118-121

16 Tervit C, Paquette L, Torneck CD et al. Proportion of healed teeth with apical periodontitis medicated with two percent chlorhexidine gluconate liquid: a caseseries study. J Endod 2009; 35(9): 1182-1185.

17 Zerella JA, Fouad AF, Spångberg LS. Effectiveness of a calcium hydroxide and chlorhexidine digluconate mixture as disinfectant during retreatment of failed endodontic cases. Oral Surg Oral Med Oral Pathol Oral Radiol Endod 2005; 100(6): 756-761.

$18 \mathrm{Ng}$ YL, Mann V, Gulabivala K. A prospective study of the factors affecting outcomes of nonsurgical root canal treatment: part 1: periapical health. Int Endod J 2011; 44(7): 583-609.

19 Mohammadi Z, Dummer PM. Properties and applications of calcium hydroxide in endodontics and dental traumatology. Int Endod J 2011; 44(8): 697-730.

20 Attam K, Talwar S, Yadav S et al. Comparative analysis of the effect of autoclaving and $10 \%$ formalin storage on extracted teeth: a microleakage evaluation. J Conserv Dent 2009; 12(1): 26-30.

21 Ozdemir HO, Buzoglu HD, Calt S et al. Effect of ethylenediaminetetraacetic acid and sodium hypochlorite irrigation on Enterococcus faecalis biofilm colonization in young and old human root canal dentin: in vitro study. J Endod 2010; 36(5): 842-846.

22 Haapasalo M, Ørstavik D. In vitro infection and disinfection of dentinal tubules. J Dent Res 1987; 66(8): 1375-1379.

23 Gomes BP, Souza SF, Ferraz CC et al. Effectiveness of $2 \%$ chlorhexidine gel and calcium hydroxide against Enterococcus faecalis in bovine root dentine in vitro. Int Endod J 2003; 36(4): 267-275.

24 Cruz-Filho AM, Sousa-Neto MD, Savioli RN et al. Effect of chelating solutions on the microhardness of root canal lumen dentin. J Endod 2011; 37(3): 358-362. 
25 Allen MJ, Edberg SC, Reasoner DJ. Heterotrophic plate count bacteria - what is their significance in drinking water? Int J Food Microbiol 2004; 92(3): 265-274.

26 Pappen FG, Shen Y, Qian W et al. In vitro antibacterial action of Tetraclean, MTAD and five experimental irrigation solutions. Int Endod J 2010; 43(6): 528-535.

27 Gomes BP, Montagner F, Berber VB et al. Antimicrobial action of intracanal medicaments on the external root surface. J Dent 2009; 37(1): 76-81.

28 Silva S, Henriques M, Martins A et al. Biofilms of non-Candida albicans Candida species: quantification, structure and matrix composition. Med Mycol 2009; 47(7): 681-689.

29 Danley DL, Polakoff J. Rapid killing of monocytes in vitro by Candida albicans yeast cells. Infect Immun 1986; 51(1): 307-313.

30 Weiger R, de Lucena J, Decker HE et al. Vitality status of microorganisms in infected human root dentine. Int Endod J 2002; 35(2): 166-171.

31 Siqueira JF Jr, de Uzeda M. Intracanal medicaments: evaluation of the antibacterial effects of chlorhexidine, metronidazole, and calcium hydroxide associated with three vehicles. J Endod 1997; 23(3): 167-169.

32 Ercan $\mathrm{E}$, Dalli M, Duülgergil CT et al. Effect of intracanal medication with calcium hydroxide and $1 \%$ chlorhexidine in endodontic retreatment cases with periapical lesion: an in vivo study. J Formos Med Assoc 2007; 106(3): 217-224.

33 Delgado RJ, Gasparoto TH, Sipert CR et al. Antimicrobial effects of calcium hydroxide and chlorhexidine on Enterococcus faecalis. J Endod 2010; 36(8): 1389-1393.

34 Garbeloglio R, Brännström M. Scanning electron microscopic investigations of human dentinal tubules. Arch Oral Biol 1976; 21(6): 355-362.
35 Waltimo TM, Ørstavik D, Sirén EK et al. In vitro yeast infection of human dentin. J Endod 2000; 26(4): 207-209.

36 Neelakantan P, Sanjeev K, Subbarao CV. Duration-dependent susceptibility of endodontic pathogens to calcium hydroxide and chlorhexidine gel used as intracanal medicament: an in vitro evaluation. Oral Surg Oral Med Oral Pathol Oral Radiol Endod 2007; 104(4): 138-141.

37 Zmener O, Pameijer $\mathrm{CH}$, Serrano SA et al. Significance of moist root canal dentin with the use of methacrylate-based endodontic sealers: an in vitro coronal dye leakage study. J Endod 2008; 34(1): 76-79.

38 de Souza-Filho FJ, Soares Ade J, Vianna ME et al. Antimicrobial effect and pH of chlorhexidine gel and calcium hydroxide alone and associated with other materials. Braz Dent J 2008; 19(1): 28-33.

39 Lin S, Kfir A, Laviv A et al. The in vitro antibacterial effect of iodine-potassium iodide and calcium hydroxide in infected dentinal tubules at different time intervals. J Contemp Dent Pract 2009; 10(2): 59-66.

(c) This work is licensed under a Creative Commons SOMERाGHS HESERVED Attribution-NonCommercial-NoDerivative Works 3.0 Unported License. To view a copy of this license, visit http:// creativecommons.org/licenses/by-nc-nd/3.0 